Abstract P190 Table 1 QVA149 versus placebo least squares mean (LSM) differences in FEV 1 and FVC

\begin{tabular}{|c|c|c|c|c|}
\hline \multirow{3}{*}{ Visit } & \multicolumn{4}{|c|}{ QVA149-placebo LSM treatment difference (SE) in mL } \\
\hline & \multicolumn{2}{|c|}{ FEV1 } & \multicolumn{2}{|c|}{ FVC } \\
\hline & 30 min post-dose & 60 min post-dose & 30 min post-dose & 60 min post-dose \\
\hline Day 1 & $156(14.2)$ & $200(16.9)$ & $221(29.7)$ & $255(35.8)$ \\
\hline Week 3 & $255(24.8)$ & $275(25.1)$ & $342(43.3)$ & $335(44.7)$ \\
\hline Week 6 & $266(26.2)$ & $275(27.2)$ & 341 (47.3) & 342 (46.5) \\
\hline Week 12 & $236(25.4)$ & $260(26.7)$ & $277(43.2)$ & $294(44.1)$ \\
\hline Week 26 & $265(31.5)$ & $270(29.6)$ & 345 (49.7) & 331 (48.1) \\
\hline Week 39 & $240(32.4)$ & $286(32.7)$ & $296(51.0)$ & $340(51.7)$ \\
\hline Week 52 & 247 (33.3) & 255 (33.6) & $289(52.9)$ & $317(56.9)$ \\
\hline
\end{tabular}

Michael Rudolf: he has been reimbursed by the following companies for speaking at educational meetings, for consultancy work, or for attending scientific conferences: Almirall, Astra-Zeneca, Boehringer Ingelheim, Chiesi, GlaxoSmithKline, Merck Sharp and Dohme, Napp, Novartis, Pfizer, Schering-Plough, and Teva.

Rajendra Mehta: he has no conflicts of interest.

\section{P191 OVA149 ONCE DAILY IMPROVES EXERCISE TOLERANCE AND LUNG FUNCTION IN PATIENTS WITH MODERATE TO SEVERE COPD: THE BRIGHT STUDY}

doi:10.1136/thoraxjnl-2012-202678.252

${ }^{1} \mathrm{KM}$ Beeh, ${ }^{2} \mathrm{~S}$ Korn, ${ }^{1} \mathrm{~J}$ Beier, ${ }^{3} \mathrm{D}$ Jadayel, ${ }^{3} \mathrm{M}$ Henley, ${ }^{4} \mathrm{~J}$ Tylek, ${ }^{4} \mathrm{I}$ Berhane, ${ }^{4} \mathrm{P} \mathrm{D}$ 'Andrea, ${ }^{4} \mathrm{D}$ Donald Banerji. 'Insaf Respiratory Research Institute, Wiesbaden, Germany; ${ }^{2}$ Pulmonary, Department, Mainz University Hospital, Mainz, Germany; ${ }^{3}$ Novartis Horsham Research Centre, Horsham, UK; ${ }^{4}$ Novartis Pharmaceuticals Corporation, East Hanover, New Jersey, USA

Introduction QVA149 is a novel once-daily fixed-dose combination of the long-acting $\beta_{2}$-agonist indacaterol and the long-acting muscarinic antagonist glycopyrronium (NVA237) in development for the treatment of chronic obstructive pulmonary disease (COPD). The BRIGHT study evaluated the effects of OVA149 versus placebo and tiotropium on exercise tolerance and lung function in patients with moderate-to-severe COPD.

Methods In a double-blind, double-dummy, 3-period crossover study, patients with moderate-to-severe COPD were randomised to QVA149 110/50 $\mu \mathrm{g}$, placebo or tiotropium $18 \mu \mathrm{g}$ once daily for 3 weeks. The primary endpoint was exercise endurance time for QVA149 versus placebo during a submaximal exercise tolerance test (SMETT) via cycle ergometry at Day 21. Dynamic inspiratory capacity (IC) at isotime during exercise, trough IC, trough $\mathrm{FEV}_{1}$ and trough forced vital capacity (FVC) were also measured.

Results Eighty five patients were randomised; mean age was 62 years, mean post-bronchodilator $\mathrm{FEV}_{1} 56 \%$ predicted. $86 \%$ patients completed the study. At Day 21, QVA149 significantly improved exercise endurance time by 59.5 seconds versus placebo $(p=0.006)$, which was of a similar magnitude to the improvement seen with tiotropium versus placebo (66.3 seconds; $p=0.002)$. More patients stopped exercise due to dyspnoea with placebo (43\% versus $36 \%$ with both QVA149 and tiotropium) and due to muscle fatigue with QVA149 and tiotropium (44-46\% versus 38\% with placebo). OVA149 also produced significant and clinically meaningful improvements in trough $\mathrm{FEV}_{1}$, dynamic IC at exercise isotime, trough IC and trough FVC versus placebo and tiotropium (table).

Conclusion OVA149 once daily provided significant and clinically meaningful improvements in exercise tolerance and lung function in patients with moderate-to-severe COPD. Despite superior bronchodilation demonstrated by QVA149 versus tiotropium, improvements seen in exercise endurance were similar, perhaps due to extra-pulmonary factors (muscle fatigue, ceiling effect). There were no safety concerns.

\section{P192 OVA149 ONCE DAILY PROVIDES SUPERIOR BRONCHODILATION VERSUS INDACATEROL, GLYCOPYRRONIUM, TIOTROPIUM AND PLACEBO: THE SHINE STUDY}

doi:10.1136/thoraxjnl-2012-202678.253

${ }^{1} \mathrm{~N}$ Barnes, ${ }^{2} \mathrm{E}$ Bateman, ${ }^{3} \mathrm{~N}$ Gallagher, ${ }^{3} \mathrm{Y}$ Green, ${ }^{3} \mathrm{R}$ Horton, ${ }^{3} \mathrm{M}$ Henley, ${ }^{4} \mathrm{D}$ Banerji. 'London Chest Hospital, Barts Health NHS Trust, London, UK; '²Department of Medicine, University of Cape Town, Cape Town, South Africa; ${ }^{3}$ Novartis Horsham Research Centre, Horsham, West Sussex, UK; ${ }^{4}$ Novartis Pharmaceuticals Corporation, East Hanover, NJ, USA

Introduction QVA149 is a novel inhaled once-daily dual bronchodilator containing a fixed-dose combination of the long-acting $\beta_{2}$-agonist indacaterol and the long-acting muscarinic antagonist NVA237 (glycopyrronium) in development for the maintenance treatment of COPD. This study evaluated the effect of QVA149 on

Abstract P191 Table 1

\begin{tabular}{lccc}
\hline & \multicolumn{3}{c}{$\begin{array}{c}\text { Treatment differences on Day 21 } \\
\text { Least squares means (95\% Confidence interval) }\end{array}$} \\
\cline { 2 - 4 } & QVA149-Placebo & QVA149-Tiotropium & Tiotropium-Placebo \\
\hline Exercise endurance time (seconds) & $59.5(17.7,101.3)^{* *}$ & $-6.7(-47.5,34.0)$ & $66.3(24.8,107.7)^{* *}$ \\
IC at isotime (L) & $0.32(0.23,0.40)^{* * *}$ & $0.14(0.05,0.22)^{* *}$ & $0.18(0.10 .0 .27)^{* * *}$ \\
Trough IC (L) & $0.19(0.09,0.29)^{* * *}$ & $0.15(0.06,0.25)^{* *}$ & $0.04(-0.06,0.13)$ \\
Trough FEV $(\mathrm{L})$ & $0.20(0.15,0.26)^{* * *}$ & $0.10(0.05,0.15)^{* * *}$ & $0.10(0.05,0.15)^{* * *}$ \\
Trough FVC (L) & $0.28(0.19,0.37)^{* * *}$ & $0.11(0.02,0.20)^{*}$ & $0.17(0.08,0.27)^{* * *}$ \\
\hline
\end{tabular}

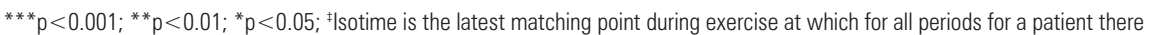
is an IC assessment; IC: inspiratory capacity; FEV $_{1}$ : forced expiratory volume in $1 \mathrm{sec}$; FVC: forced vital capacity. 